\title{
Production and Utilization of Surface Engineered SPIONS for Enhanced Removal of Dye from Water ${ }^{\dagger}$
}

\author{
Hawwa Hashma Ali ${ }^{1}$, Faradjeva Etel ${ }^{1, *}$ \\ 1 School of Bioscience, Faculty of Medicine, Bioscience and Nursing, MAHSA University, Jalan SP2, Bandar Saujana \\ Putra, 42610, Jenjarom, Selangor, Malaysia \\ * Correspondence: faradzh.etel@gmail.com; \\ $\dagger$ Presented at International e-Conference on Bioengineering for Health and Environment (ICBHE 2020)
}

Received: 5.07.2020; Revised: 10.07.2020; Accepted: 12.07.2020; Published: 15.07.2020

\begin{abstract}
SPIONs, being the only metal oxide nanoparticles clinically approved, have shown a great promise in the various clinical applications, including environmental remediation, specifically water treatment. In this study, SPIONs are produced by the chemical co-precipitation method used for dye removal studies, where isotherm kinetics were studied. In conclusion, it was shown that both naked and coated SPIONs successfully demonstrated the removal of crystal violet from the water, thereby enabling to apply SPIONs for the treatment of contaminated water with textile dyes.
\end{abstract}

Keywords: SPIONs; co-precipitation; isotherm; water treatment.

(C) 2020 by the authors. This article is an open-access article distributed under the terms and conditions of the Creative Commons Attribution (CC BY) license (https://creativecommons.org/licenses/by/4.0/).

\section{Funding}

This research received no external funding.

\section{Acknowledgments}

This research has no acknowledgment.

\section{Conflicts of Interest}

The authors declare no conflict of interest. 